\title{
Prevalence and antimicrobial susceptibility of enterotoxigenic extra-intestinal Bacteroides fragilis among 13-year collection of isolates in Kuwait
}

\author{
Wafaa Jamal ${ }^{1 *}$ (D), Fatima Bibi Khodakhast ${ }^{1}$, Ameerah AlAzmi ${ }^{1}$, József Sóki ${ }^{2}$, Ghayda AlHashem ${ }^{1}$ and \\ Vincent O. Rotimi ${ }^{1}$
}

\begin{abstract}
Background: Some strains of Bacteroides fragilis species are associated with diarrhea as a result of enterotoxin production (bft or fragilysin). Fragilysin is activated by C11 protease (fpn) and together with C10 protease (bfp) play a significant role in its invasiveness. The objectives of this study were to investigate the proportion of clinical isolates from extra-intestinal sources that are toxin producers and characterize the genes mediating toxin production. Clinical isolates submitted to our reference laboratory over the last 13 years were screened for toxin production using PCR technique. All stool isolates were excluded. The isolates were tested for their susceptibility to 8 antimicrobial agents by E test. Carbapenem resistance gene cfiA was detected by PCR.

Results: A total of 421 B. fragilis isolates were viable. Out of these, bft was detected in 210 (49.9\%) isolates. Of the 210 bft-positive isolates, 171 (81.4\%), 33 (15.7\%) and 6 (2.8\%) harbored bft-1, bft-2, and bft-3 genes, respectively. Twenty (9.5\%) of the bft-positive strains originated from bloodstream infections. Twenty-five, 20 and 9 strains harbored bfp-1, bfp-2 and bfp-3 gene, respectively. Two, 3, 4 bfp isotypes were detected simultaneously in some of strains. The resistance rates against amoxicillin-clavulanic acid was $32 \%$, clindamycin $62 \%$, cefoxitin $26 \%$, imipenem $11 \%$, meropenem $17 \%$, metronidazole $4 \%$, piperacillin $61 \%$ and tigecycline $14 \%$. A chromosomally located cfiA gene that encode metallo- $\beta$-lactamase was identified in only 34 isolates (16.2\%).

Conclusions: The prevalence of enterotoxin-producing $B$. fragilis was high among the extra-intestinal isolates. Metronidazole was the most active agent against all isolates. There was no statistically significance difference between resistance rates among bft-positive and bft-negative isolates except for clindamycin.
\end{abstract}

Keywords: Bacteroides fragilis, Enterotoxin, Carbapenem-resistance, Kuwait

\section{Backgrounds}

Bacteroides species are obligate anaerobic members of the normal microbiota of the human gut. They are the commonest anaerobic bacteria associated with clinical infections particularly those associated with infections of the mucous membranes and adjacent tissues [1]. $B$. fragilis is a type species of the Bacteroides genus whose numerical population is far less than the other

\footnotetext{
* Correspondence: wjamal@hsc.edu.kw

${ }^{1}$ Department of Microbiology, Faculty of Medicine, Kuwait University, P. O. Box 24923, 13110 Safat, Kuwait

Full list of author information is available at the end of the article
}

Bacteroides spp., (e.g. B. thetaiotaomicron, B. distasonis and $B$. vulgatus), in the normal gut microbiota. However, paradoxically, it is the most common non-spore forming anaerobic bacteria found in routine clinical specimens, e.g. those obtained from deep intra-abdominal abscesses, suppurative skin and soft tissue infections, infections following intra-abdominal and vaginal post-hysterectomy surgeries [1]. Recent studies on gut microbiota have suggested that $B$. fragilis can be the dominant species associated/adherent to the colonic mucosa in healthy individuals [2] contrary to the old believe that its

(c) The Author(s). 2020 Open Access This article is distributed under the terms of the Creative Commons Attribution 4.0 International License (http://creativecommons.org/licenses/by/4.0/), which permits unrestricted use, distribution, and 
contribution to the anaerobic microbiota of the gut is minimal based on studies on fecal samples.

An important virulence factor of $B$. fragilis is an enterotoxin. Enterotoxin-producing $B$. fragilis (ETBF) strain was first isolated from the stool of neonatal lambs with diarrhea in 1984 [3]. ETBF was later found to cause diarrhea in humans and has been defined as one of the 6 possible causes of diarrhea in children aged 1-5 years [4]. It has also been isolated infrequently from stool specimens of symptomatic adult patients [5]. Although some reports have put the prevalence of extra-intestinal ETBF at $6.2-38 \%[6,7]$, the prevalence of ETBF strains among $B$. fragilis isolates from diarrheagenic and extraintestinal clinical samples in Kuwait is unknown. The enterotoxin produced by $B$. fragilis is also known as fragilysin. It is a zinc-dependent, non-lethal, heat labile metalloprotease of about $20 \mathrm{kDa}$ [8] which acts by cleaving the E-cadherin protein of zonula adherens and tight junctions in the intestinal epithelial cells leading to rearrangement of the actin of the cytoskeleton of the epithelial cells $[9,10]$. So far the gene mediating fragilysin (bft) has been well characterized into 4 isotypes, namely $b f t-1, b f t-2, b f t-3$ and bft-4 [11]; the latter is mainly found in the Far East [7].

In addition, $B$. fragilis has another virulence factor, an endotoxin/lipopolysaccharide (LPS) with a demonstrable toxicity [12]. Once B. fragilis is exposed to antibiotics, it liberates endotoxin more than other Bacteroides species which may explain why this species is associated with clinical infections and higher mortality rate [13].

Some studies have demonstrated an association between increased prevalence of ETBF strains and inflammatory bowel diseases, such as Crohn's disease and ulcerative colitis [14], while a possible pathogenic role in the etiology of colorectal cancer [15] and bacteremia $[16,17]$ has been suggested. Two cystein peptidase types with pathogenic role have recently been described: $b f p 1-$ 4 genes encoding $\mathrm{C} 10$ peptidase and $f p n$ gene encoding C11 peptidase (fragipain). Potential link between C10 peptidase and the pathogenesis of inflammatory bowel disease and sepsis has been documented and fragipain has been shown to activate $B$. fragilis enterotoxin $[17,18]$.

The susceptibility of $B$. fragilis to metronidazole and carbapenem has been excellent with few anecdotal reports of resistance emerging in the literature over the last 3 decades [19-21]. They have remained the drugs extensively used for the treatment of infections caused by this opportunistic pathogen. The emerging reports of $B$. fragilis isolates resistant to these drugs are causing increasing concern to the infectious diseases and clinical microbiology experts worldwide. The trend of resistance to these drugs by $B$. fragilis in our country, and elsewhere in the Gulf countries, is not clearly defined at molecular level.
This study was designed to investigate the prevalence of ETBF and the $b f t$ genes among $B$. fragilis isolates collected over 13 years in the Anaerobic Reference Laboratory and to determine the presence of genes mediating carbapenemase (cfiA) production among carbapenemresistant $B$. fragilis isolates. It was also planned to investigate the prevalence of $b f p 1-4$ and $f p n$ genes in $b f t$-positive and $b f t$-negative strains.

\section{Results}

\section{Bacterial isolates}

A total of 421 B. fragilis isolates were collected from the following different sources: wound infections (WIs), lower respiratory tract infections (LRTIs), bloodstream infections (BSIs), biopsy specimens, urine, and bile. As shown in Table 1, out of the 421 isolates, 210 (49.9\%) harbored the bft gene. The majority of the bft-positive isolates were from WIs, followed by LRTIs, BSIs and biopsy specimens (BS).

The ages ranged from 1 month to 94 years (mean, 52 years). Of the 210 patients, 137 (65.2\%) were males and $73(34.8 \%)$ were females. Out of 39 isolates derived from patients with BSIs, 20 (51.2\%) were positive for $b f t$ gene. The presence of $b f p 1-4$ (C 10 protease gene) and fpn (C11 protease gene) were investigated in the $210 \mathrm{bft}$-positive $B$. fragilis strains using PCR. As shown in Table 2, the distribution of C10 protease $(b f p)$ genes was the following: 25 (11.9\%) isolates harbored $b f p-1$ gene, 20 (9.5\%) bfp-2 and 9 (4.2\%) bfp-3 isotypes alone.

Of the 210, 59 (28.1\%) strains carried both $b f p-1$ and $b f p-2$ simultaneously, and $31(14.7 \%)$ strains were positive for $b f p-1, b f p-2$ and $b f p-3$. In all, 46 (21.9\%) isolates did not carry any of the tested $b f p$ genes.

As shown in Table 3, 170 (80\%) B. fragilis were positive for $f p n$ (C11 protease) gene among the $210 \mathrm{bft}$-positive strains, 34 (20\%) of which were cfiA-positive.

Table 1 Distribution of $B$. fragilis bft subtypes among different sources of infections

\begin{tabular}{lllll}
\hline \multirow{2}{*}{ Sources } & \multicolumn{2}{l}{ Number (\%) } & Total (\%) \\
\cline { 2 - 4 } & bft-1 & $b f t-2$ & $b f t-3$ & \\
\hline Wound infection & $105(50)$ & $16(7.6)$ & $5(2.4)$ & $126(60)$ \\
Respiratory tract infection & $30(14.3)$ & $11(5.2)$ & 0 & $41(19.5)$ \\
Bloodstream infection & $16(7.6)$ & $4(1.9)$ & 0 & $20(9.5)$ \\
Biopsy & $17(8.1)$ & $2(1)$ & $1(0.5)$ & $20(9.5)$ \\
Urine & $1(0.5)$ & 0 & 0 & $1(0.5)$ \\
Bile & $1(0.5)$ & 0 & 0 & $1(0.5)$ \\
Unknown & $1(0.5)$ & 0 & 0 & $1(0.5)$ \\
Total & $171(81.4)$ & $33(15.7)$ & $6(2.9)$ & $210(100)$ \\
\hline
\end{tabular}


Table 2 Distribution of bfp genes among 210 bft-positive $B$. fragilis strains

\begin{tabular}{|c|c|}
\hline bfp gene in B. fragilis strains & No (\%) \\
\hline bfp1-positive & $25(11.9)$ \\
\hline bfp2-positive & $20(9.5)$ \\
\hline bfp3-positive & $9(4.2)$ \\
\hline bfp4 positive & $0(0)$ \\
\hline$b f p 1$ and $b f p 2$-positive & $59(28.1)$ \\
\hline$b f p 1$ and bfp3-positive & $8(3.8)$ \\
\hline$b f p 1$ and $b f p 4$-positive & $1(0.47)$ \\
\hline$b f p 2$ and bfp3-positive & $3(1.4)$ \\
\hline$b f p 1, b f p 2$ and bfp3-positive & $31(14.7)$ \\
\hline$b f p 1, b f p 2$ and bfp4-positive & $2(0.95)$ \\
\hline bfp $1, b f p 2, b f p 3$ and bfp4-positive & $6(12.6)$ \\
\hline bfp-negative & $46(21.9)$ \\
\hline
\end{tabular}

\section{Antimicrobial susceptibility testing and distribution of} resistance cfiA gene

MIC range, $\mathrm{MIC}_{50} \mathrm{MIC}_{90}$ and percentage of resistance of the tested antibiotics are shown in Table 4.

A total of $261(62 \%)$ and 257 (61.1\%) were resistant to clindamycin and piperacillin, respectively. Amoxicillinclavulanic acid and cefoxitin had unacceptable high MIC values: 135 (32.1\%) and $110(26.1 \%)$ were resistant, respectively. Resistance rates to metronidazole, tigecycline, imipenem and meropenem were $4,14,11$, and $17 \%$, respectively. When resistance rates among bft-positive and $b f t$-negative strains were compared, only resistance to clindamycin and tigecycline were higher among bft-positive than the $b f t$-negative strains but only resistance to clindamycin attained statistically significant level $(P=$ 0.048: CI 18.1-23.21) (Table 5).

Table 3 Distribution of $f p n$ and $b f p 1-4$ genes in the cfiApositive and cfiA-negative $B$. fragilis

\begin{tabular}{lll}
\hline B. fragilis strains (total no) & $\begin{array}{l}\text { cfiA-positive } \\
\text { (no=34) }\end{array}$ & $\begin{array}{l}\text { cfiA-negative } \\
\text { (no =176) }\end{array}$ \\
\hline bfp1- positive (25) & 11 & 14 \\
bfp2- positive (20) & 1 & 19 \\
bfp3- positive (9) & 0 & 9 \\
bfp4- positive (0) & 0 & 0 \\
bfp1 and bfp2-positive (60) & 12 & 48 \\
bfp1 and bfp3-positive (8) & 0 & 8 \\
bfp1 and bfp4-positive (1) & 0 & 1 \\
bfp2 and bfp3-positive (3) & 0 & 3 \\
bfp1, bfp2 and bfp3-positive (31) & 6 & 25 \\
bfp1, bfp2, bfp4-positive (2) & 2 & 0 \\
bfp1, bfp2, bfp3 and bfp3-positive (6) & 1 & 5 \\
bft-negative isolates (46) & 1 & 45 \\
fpn-positive strains (170) & 34 & 136 \\
\hline
\end{tabular}

Further analysis showed that 72 (34.2\%) of $b f t$-positive isolates were multidrug resistant (MDR), that is nonsusceptibility to at least one agent in 3 or more different antimicrobial categories [22]. Out of the 72 MDR isolates, 64 (88.9\%) and 8 (11.1\%) were bft-1 and bft-2 subtypes, respectively. None of the $b f t-3$ positive strains was multidrug-resistant.

Thirty-four $(8.1 \%)$ and 19 (4.5\%) of 421 isolates were resistant to meropenem and imipenem, respectively. Mechanism of carbapenem resistance revealed that all the carbapenem resistant strains were positive for the cfiA gene. This equates with $16.2 \%$ of the $210 \mathrm{bft}$-positive isolates. The sources of these resistant isolates were WIs [23], biopsy samples [4], BSI [3] and LRTIs [3]. A cfiA gene was detected in one $B$. fragilis strain that showed susceptibility to both imipenem and meropenem with MIC of 2 and $4 \mu \mathrm{g} / \mathrm{ml}$, respectively. This isolate was cultured from a patient with wound infection. In addition, one $B$. fragilis isolate was resistant to both imipenem and meropenem with MIC of 8 and $>32 \mu \mathrm{g} / \mathrm{ml}$, respectively, but $c f i A$-negative.

\section{Discussion}

B. fragilis can cause serious clinical infections thought to be related to the production of enterotoxin $(b f t)$, among other virulence factors. This toxin is activated by $\mathrm{C} 11$ $(f p n)$ and C10 proteases $(b f p)$ which help in the invasiveness of the organism. It has been shown that $b f t$-positive B. fragilis are more invasive than bft-negative isolates in different types of infections and that blood culture isolates are more likely to carry $b f t$ enterotoxin gene than other isolates [24]. The prevalence of $49.9 \%$ for the enterotoxin producing-extra intestinal $B$. fragilis in our study is relatively high when compared with the figures of $14.4 \%$ reported in Poland [25], 18.6\%, in Japan [16], $6.2-38 \%$ in USA [6, 7], and $13-25 \%$ in Hungary $[11,26]$. Our data showed that the majority (81.4\%) of the isolates contained bft-1 isotype compared with $15.7 \%$ of $b f t-2$ and $2.9 \%$ bft-3 isotypes. It is pertinent to note that no $b f t-4$ isotype strain was detected in this series. This order of prevalence of the isotypes is partially concordant with previous reports by Scotto d'Abusco et al., [27], Sarvari et al., [11] and Kierzkowska et al., [25]. In their study, Sarvari and colleagues [11] from Hungary reported the prevalence of $10 \%$ for the $b f t-1$ isotype compared with $3 \%$ bft-2 but, unlike our study, they did not detect $b f t-3$ isotype. This difference in the distribution of $b f t$ gene may be related to the severity of illness, prior antimicrobial therapy, type of the diet and thus gut flora and the method used to detect the enterotoxin. In addition, more than half (51.2\%) of the isolates from bloodstream infections in Kuwait were enterotoxin producers which was much higher than previous reports from the USA and Japan $(19-28.1 \%$ by Claros et al., 2006 and Kato 
Table 4 Antimicrobial susceptibility for 421 B. fragilis isolates

\begin{tabular}{|c|c|c|c|c|}
\hline Antimicrobial agent (breakpoint in $\mu \mathrm{g} / \mathrm{ml}$ ) & Range & $\mathrm{MIC}_{50}$ & $\mathrm{MIC}_{90}$ & $\%$ of resistance \\
\hline Amoxicillin-clavulanic acid (4) & $0.125->256$ & 2 & $>256$ & 32 \\
\hline Clindamycin (2) & $<0.016->256$ & $>256$ & $>256$ & 62 \\
\hline Imipenem (4) & $0.023->32$ & 0.25 & 6 & 11 \\
\hline Meropenem (4) & $0.023->32$ & 0.5 & $>32$ & 17 \\
\hline Metronidazole (8) & $0.023->256$ & 1 & 2 & 4 \\
\hline Piperacillin (16) & $0.19->256$ & $>256$ & $>256$ & 61 \\
\hline Cefoxitin (16) & $0.032->256$ & 8 & $>256$ & 26 \\
\hline Tigecycline (4) & $0.094-32$ & 1 & 8 & 14 \\
\hline
\end{tabular}

et al, 1996, respectively) $[16,28]$. In our study, simultaneous harboring of 2, 3 and 4 bfp isotypes occurred in 71, 33 and 6 isolates, respectively, which is higher than those reported by Sarvari et al., and among the most $b f t$-positive strains, $b f p-1$ was the most prevalent isotype. This was discordant with the results of the study reported by Sarvari et al., in which the most common isotype was $b f p-2$ [11]. In addition, they did not find 4 isotypes in the same isolates [11]. Almost half of our isolates were $b f t$-negative although they were pathogenic in a number of clinical scenarios. The explanation for this may be due to production of other virulence factors e.g. lipopolysaccharide (LPS) endotoxin especially after exposure to antibiotics [13] or both LPS and capsule that act as adhesion allowing the organism to become established at the site of infection and providing a nidus for abscess formation [1, 24].

The majority (60\%) of $b f t$-positive $B$. fragilis isolates were from wound infections which was higher than that reported from Germany and USA $(10 \% ; 24)$ and from Hungary $(51 \% ; 11)$, but lower than that reported in Warsaw, Poland $(67.5 \% ; 28)$. This probably implies that $b f t$-positive strains are more pathogenic in wound infections than the $b f t$-negative strains.

Antimicrobial resistance is a growing problem all over the world including resistance phenomena by $B$. fragilis.
In this study, resistance to clindamycin (62\%) was at an unacceptable level. This shows that B. fragilis in Kuwait are much more highly resistant to this agent than discordant reports elsewhere, such as $28.5 \%$ in Europe [29], 48.9\% in Taiwan [30], 29.9\% in USA [31] and $36.6 \%$ in China [32]. It is conceivable that the over use and abuse of this agent in almost all government and private hospitals as well as dental clinics in Kuwait is responsible for the alarming high resistance rate. Other relatively high unacceptable resistance level of $26 \%$ was recorded against cefoxitin. This is very disturbing finding as this agent is massively used for surgical prophylaxis by most of our surgeons in the country. Its empirical use must therefore be called to question. Metronidazole was the most active non$\beta$-lactam drug with $4 \%$ resistance rate. Despite being an active agent in our country, this resistance rate is much higher than those reported from other countries around the world [29-32]. Although the resistance rate to amoxicillin-clavulanic acid in our study is marginally higher than those reported around the globe, it is nonetheless at a very uncomfortable high level (32\%). Another very interesting but disturbing finding, in our study, is the relatively high tigecycline resistance level of $14 \%$. This is too high when compared with findings reported in the European study

Table 5 Antimicrobial resistance among bft-positive (210) and bft-negative (211) B. fragilis

\begin{tabular}{|c|c|c|c|c|c|c|c|}
\hline \multirow[t]{2}{*}{ Antibiotic (breakpoint in $\mu \mathrm{g} / \mathrm{ml}$ ) } & \multicolumn{3}{|c|}{ No (\%) of resistant bft-positive B. fragilis } & \multirow{2}{*}{$\begin{array}{l}\text { Total no (\%) } \\
\text { of resistant } \\
\text { bft-positive } \\
\text { B. fragilis }\end{array}$} & \multirow{2}{*}{$\begin{array}{l}\text { No (\%) of } \\
\text { resistant } \\
\text { bft-negative } \\
\text { B. fragilis }\end{array}$} & \multirow[t]{2}{*}{$P$ value } & \multirow{2}{*}{$\begin{array}{l}\text { Confidence } \\
\text { interval (Cl) }\end{array}$} \\
\hline & $\overline{b f t-1}$ & $b f t-2$ & $b f t-3$ & & & & \\
\hline Amoxicillin-clavulanic acid (4) & $56(26.7)$ & $2(1)$ & $2(1)$ & $60(28.8)$ & $37(34.6)$ & 0.354230 & {$[-15.52,27.12]$} \\
\hline Clindamycin (2) & $119(56.7)$ & $20(9.5)$ & $3(1.4)$ & $142(67.6)$ & $120(56.9)$ & 0.048847 & {$[-1.81,23.21]$} \\
\hline Imipenem (4) & $16(7.6)$ & $1(0.5)$ & $1(0.5)$ & $18(8.6)$ & $27(12.8)$ & 0.482089 & {$[-18.50,26.90]$} \\
\hline Meropenem (4) & $31(14.8)$ & $2(1)$ & $1(0.5)$ & $34(16.2)$ & $39(18.5)$ & 0.479721 & {$[-17.83,22.43]$} \\
\hline Metronidazole (8) & $10(4.8)$ & $2(1)$ & 0 & $12(5.7)$ & $6(2.8)$ & 0.182954 & {$[-28.21,34.01]$} \\
\hline Piperacillin (16) & $102(48.6)$ & $15(7.1)$ & $4(1.9)$ & $121(57.6)$ & $136(64.5)$ & 0.157430 & {$[-5.81,19.61]$} \\
\hline Cefoxitin (16) & $36(17.1)$ & $2(1)$ & $1(0.5)$ & 39 (18.6) & 70 (33.2) & 0.079984 & {$[-3.85,33.05]$} \\
\hline Tigecycline (4) & $29(13.8)$ & $5(2.4)$ & $3(1.4)$ & 37 (17.6) & $21(10)$ & 0.345271 & {$[-13.89,29.09]$} \\
\hline
\end{tabular}


(1.8\%) by Nagy et al., [29], 0\% in Taiwan study [30] and $5.4 \%$ in USA study [31].

B. fragilis resistance to carbapenem is often associated with production of a class $B$ metallo- $\beta$ - lactamase encoded by the chromosomal cfiA gene, in addition to outer membrane permeability barrier mechanism [33]. In our study, 11 and $17 \%$ of $B$. fragilis were resistant to imipenem and meropenem, respectively which are much higher than those reported in Europe (1.2\% for imipenem) [29], USA (1.1\% for imipenem and 2.5\% meropenem) [31], Taiwan (8.5\% imipenem and 9.9\% meropenem) [30]. However, the B. fragilis resistance to imipenem and meropenem in our study were lower than reported in China (22.7 and $18.2 \%$, respectively) [32]. One of our B. fragilis isolate was resistant to both imipenem and meropenem in the absence of $c f i A$ gene which was similar to the report in studies by Soki et al., [34]. Our speculation is that this may be due to other mechanism of resistance, perhaps out membrane permeability problem. Detection of $16.2 \%$ cfiA gene is higher than $1.8 \%$ which was reported in Poland [25] but lower than that of $36.4 \%$ reported in China [32]. A cfiA gene was detected in one $B$. fragilis isolate that showed susceptibility to both imipenem and meropenem. This has been reported previously $[35,36]$ and can be explained by the absence of insertion sequence upstream the gene leading to poor expression of cfiA gene.

Limitation of the study include retrospective collection of isolates and clinical data. Response to therapy could not be determined and insertion sequence elements were not done in the cfiA-positive isolates. Although to our knowledge the most common mechanism of carbapenem resistance in $B$. fragilis is the production of cfiA metallo- $\beta$-lactamase via activation of the cfiA gene by IS elements (high level resistance) or by activation of its putative own promoter other possible mechanisms, such as other carbapenemase genes and $\mathrm{AmpC}$ gene, were not investigated.

\section{Conclusions}

The prevalence of enterotoxin-producing B. fragilis strains among the clinical isolates of extra-intestinal origin was very high in our study. There was no statistically significance difference in the antibiotic resistance rates among $b f t$-positive and $b f t$-negative isolates except for clindamycin. In this study, metronidazole was the most active antimicrobial agent against enterotoxigenic $B$. fragilis isolates.

\section{Methods}

\section{Study design}

This was a multicenter prospective investigational study of stored B. fragilis isolates from 6 hospital microbiological laboratories (Mubarak, Amiri, Al Babtain, Ibn Sina, Adan and Maternity hospitals) in Kuwait. All clinical isolates obtained from proven cases of infections stored at $-80^{\circ} \mathrm{C}$ were resuscitated and viable strains investigated for enterotoxin production.

\section{Bacterial strains}

The bacterial strains were isolates collected during a 13years period, from 2006 through 2018, and stored in the Anaerobe Reference Laboratory, Faculty of Medicine, Kuwait University. The viable B. fragilis isolates were from proven cases of intra-abdominal infections, lower respiratory tract infections, bloodstream infections, wound infections and abscesses, managed in the 6 hospitals. All isolates were stored, in Brain Heart Infusion (BHI, Oxoid limited, Basingstoke, Hampshire, UK) broth containing $20 \%$ glycerol, at $-80^{\circ} \mathrm{C}$. During our investigation, isolates were subcultured on Brucella blood agar (Becton Dickinson, Heidelberg, Germany) incubated for $48 \mathrm{~h}$ at $37^{\circ} \mathrm{C}$, in an Anoxomat Anaerobic WS800 system $^{\text {tw }}$ (MART Microbiology BV, Lichtenvoorde, Netherlands), in an atmospheric condition of $85 \%$ $\mathrm{N}_{2}, 10 \% \mathrm{CO}_{2}, 5 \% \mathrm{H}_{2}$. The identification was confirmed by a Matrix Assisted Laser Desorption/Ionization-Time of Flight Mass Spectrometry (MALDI-TOF MS; bioMérieux, L'Etoile, Marcy, France) analysis.

\section{Antimicrobial susceptibility testing (AST)}

The susceptibility of the isolates to 8 anti-anaerobic antibiotics was investigated by determining the minimum inhibitory concentrations (MICs) of the antibiotics using the $\mathrm{E}$ test method (bioMérieux) according to manufacturer's instructions. The antibiotics tested were the following: amoxicillin-clavulanic acid, clindamycin, cefoxitin, imipenem, meropenem, metronidazole, piperacillin and tigecycline. Susceptibility profiles of the isolates were determined according to the interpretative criteria recommended by the CLSI, 2018 [37]. B. fragilis ATCC 25285, and B. thetaiotaomicron ATCC 29741 were included as control in each run. Results for the isolates were accepted if the quality control strains results were within the established CLSI ranges (CLSI, 2018). $\mathrm{MIC}_{50}, \mathrm{MIC}_{90}$ and percentage of resistance were calculated.

\section{Molecular detection of fragilysin (bft) gene}

Using previously published procedure, a PCR was performed for the detection of $b f t$ gene in all the $B$. fragilis isolates using $\mathrm{bftF}$ and $\mathrm{bftR}$ primers [18]. The genes, primer sequences, cycling conditions are shown in Table 6. The following positive controls were used: $B$. fragilis R19811 (bft-1), B. fragilis 1 ATCC 43858 (bft-2), and B. fragilis GAI 96462 (bft-3). Sequencing of the amplicons of the internal fragments of $b f t-1, b f t-2$ and $b f t-3$ were performed using a GenAmp PCR system 9700 by cycling sequencing with BigDye ${ }^{\circ}$ Terminator (AB Applied Biosystems, Carlsbad, California, USA). 
Table 6 The genes, primer sequence, cycling condition and reference for fragilysin bft gene, fpn, bfp 1-4 genes and cfiA carbapenemase gene

\begin{tabular}{|c|c|c|c|c|}
\hline Gene & Primer sequence ( $5^{\prime}$ to $3^{\prime}$ ) & Cycling condition & Product size (bp) & Reference \\
\hline$b f t$ & $\begin{array}{l}\text { bftF: CGAACTCGGTTTATGCAGTT } \\
\text { bftR: GGATACATCAGCTGGGTTGT }\end{array}$ & $\begin{array}{l}95^{\circ} \mathrm{C} / 5 \mathrm{~min} \text {; followed by } 35 \text { cycles of } 95^{\circ} \mathrm{C} / 45 \mathrm{~s} \text {, } \\
56^{\circ} \mathrm{C} / 1 \mathrm{~min}, 72^{\circ} \mathrm{C} / 45 \mathrm{~s}, 72^{\circ} \mathrm{C} / 7 \mathrm{~min}\end{array}$ & 295 & [18] \\
\hline$f p n$ & $\begin{array}{l}\text { C11_protease_F: ATTCGGCCGATGCAAATGTG } \\
\text { C11_protease_R: CGGAATCTCGGTAGGGAAC }\end{array}$ & $\begin{array}{l}95^{\circ} \mathrm{C} 5 \mathrm{~min} \text {; followed by } 35 \text { cycles of } 95^{\circ} \mathrm{C} / 45 \mathrm{~s} \text {; } \\
56^{\circ} \mathrm{C} / 1 \mathrm{~min} ; 72^{\circ} \mathrm{C} / 45 \mathrm{~s}, 72^{\circ} \mathrm{C} / 7 \mathrm{~min}\end{array}$ & 290 & [11] \\
\hline bfp 1 & $\begin{array}{l}\text { C10_protease_F1: GCGGTGAACAAAGAACGACA } \\
\text { C10_protease_R1: TCGCCTGAGCAACTGCAATA }\end{array}$ & $\begin{array}{l}95^{\circ} \mathrm{C} 10 \mathrm{~min} ; 35 \mathrm{cycles} \text { of } 95^{\circ} \mathrm{C} / 15 \mathrm{~s} ; 59^{\circ} \mathrm{C} / 30 \mathrm{~s} ; \\
72^{\circ} \mathrm{C} / 47 \mathrm{~s} ; 72^{\circ} \mathrm{C} / 7 \mathrm{~min}\end{array}$ & 153 & [11] \\
\hline$b f p 2$ & $\begin{array}{l}\text { C10_protease_F2: CGTACCAATTGCAATTGCGC } \\
\text { C10_protease_R2: AGCTCCCGTGGCTITATCTT }\end{array}$ & $\begin{array}{l}95^{\circ} \mathrm{C} 10 \mathrm{~min} ; 35 \text { cycles of } 95^{\circ} \mathrm{C} / 15 \mathrm{~s} ; 59^{\circ} \mathrm{C} / 30 \mathrm{~s} \text {; } \\
72^{\circ} \mathrm{C} / 47 \mathrm{~s} ; 72^{\circ} \mathrm{C} / 7 \mathrm{~min}\end{array}$ & 178 & [11] \\
\hline$b f p 3$ & $\begin{array}{l}\text { C10_protease_F3: TTTGGAGTAGCAGCAGCAGA } \\
\text { C10_protease_R3: TाTCTGGTTCGGGTGTTC }\end{array}$ & $\begin{array}{l}95^{\circ} \mathrm{C} 10 \mathrm{~min} ; 35 \text { cycles of } 95^{\circ} \mathrm{C} / 15 \mathrm{~s} ; 59^{\circ} \mathrm{C} / 30 \mathrm{~s} \text {; } \\
72^{\circ} \mathrm{C} / 47 \mathrm{~s} ; 72^{\circ} \mathrm{C} / 7 \mathrm{~min}\end{array}$ & 194 & [11] \\
\hline bfp 4 & $\begin{array}{l}\text { C10_protease_F4: TACAACGGTGTTGGTGCAAG } \\
\text { C10_protease_R4: ACACAAATGCGCCACTTCAT }\end{array}$ & $\begin{array}{l}95^{\circ} \mathrm{C} 10 \mathrm{~min} ; 35 \mathrm{cycles} \text { of } 95^{\circ} \mathrm{C} / 15 \mathrm{~s} ; 59^{\circ} \mathrm{C} / 30 \mathrm{~s} ; \\
72^{\circ} \mathrm{C} / 47 \mathrm{~s} ; 72^{\circ} \mathrm{C} / 7 \mathrm{~min}\end{array}$ & 126 & [11] \\
\hline cfiA & $\begin{array}{l}\text { cfiF: AATCGAAGGATGGGGTATGG } \\
\text { cfiR: CGGTCAGTGAATCGGTGAAT }\end{array}$ & $\begin{array}{l}95^{\circ} \mathrm{C} / 10 \mathrm{~min}, \text { followed by } 35 \text { cycles of } 95^{\circ} \mathrm{C} / 15 \mathrm{~s} \text {, } \\
59^{\circ} \mathrm{C} / 30 \mathrm{~s}, 72^{\circ} \mathrm{C} / 7 \mathrm{~s} ; 72^{\circ} \mathrm{C} / 7 \mathrm{~min}\end{array}$ & 302 & [38] \\
\hline
\end{tabular}

Molecular detection of cfiA carbapenemase-producing gene Production of carbapenemase by the isolates was detected in selected number of strains with very high MIC values for meropenem/imipenem using modified Hodge test. All $b f t$-positive strains as well as imipenem and/or meropenem resistant $B$. fragilis (i.e. $\mathrm{MIC} \geq 4 \mu \mathrm{g} / \mathrm{ml}$ ) were screened for the presence of $c f i$ A gene and confirmed by PCR, using published primers [38]. The genes, primer sequences, cycling conditions are given in Table 6. PCR was carried out in a volume of $25 \mu \mathrm{l}$. The PCR mix was obtained from Qiagen (Hilden, Germany) and the supernatant of boiled bacterial cells was used as a source of DNA template and the concentration of each primer was $25 \mathrm{pmol}$. PCR products was separated by agarose gel electrophoresis and stained with $1 \%$ ethidium bromide (Bio-Rad, Hercules, CA, USA) and visualized by UV light.

\section{Molecular analysis of C10 protease (bfp1-4) and C11 protease (fragipain, fpn) genes}

For all $b f t$-positive isolates, $b f p 1-4$ and $f p n$ genes in the $\mathrm{C} 10$ and $\mathrm{C} 11$ proteases, respectively, were investigated. They were investigated by PCR using the genes, primer sequences, cycling conditions given in Table 6 and the following control strains: B. fragilis 638R (bfp1-4) and $B$. fragilis ATCC 43859 (fpn) were included [17, 23, 28].

\section{Statistical evaluation}

The EpiCalc 2000, version 1.02 (Brixton Heath, Llanidloes, Powys, Wales, UK) was used to compare two proportionspercentages with $95 \%$ confidence interval and one sided $P$-value.

\section{Abbreviations}

AST: Antimicrobial susceptibility testing; $B$. distasonis: Bacteroides distasonis; $B$. fragilis: Bacteroides fragilis; $B$. thetaiotaomicron: Bacteroides thetaiotaomicron; $B$. vulgatus: Bacteroides vulgatus; bfp: C10 protease; bft: fragilysin enterotoxin;
BHI: Brain Heart Infusion; BS: Biopsy specimens; BSIs: Bloodstream infections; cfiA: carbapenem resistance gene; Cl: Confidence interval; CLSI: Clinical and Laboratory Standards Institute; $\mathrm{CO}_{2}$ : Carbon dioxide; DNA: Deoxyribonucleotide; ETBF: Enterotoxin-producing Bacteroides fragilis; fpn: C11 protease; $\mathrm{H}_{2}$ : Hydrogen; kDa: KiloDalton; LPS: Lipopoltsaccharide; LRTI: Lower respiratory tract infections; MALDI-TOF MS: Matrix Assisted Laser Desorption/lonizationTime of Flight Mass Spectrometry; MDR: Multidrug resistant; MIC: Minimum inhibitory concentrations; $\mathrm{MIC}_{50}$ : Minimum inhibitory concentrations that inhibited $90 \%$ of the isolates; $\mathrm{MIC}_{90}$ : Minimum inhibitory concentrations that inhibited $90 \%$ of the isolates; $\mathrm{N}_{2}$ : Nitrogen; PCR: Polymerase chain reaction; Wls: Wound infections

\section{Acknowledgements}

The authors thank all microbiology departments in the 6 hospitals for sending us the strains.

\section{Authors' contributions}

WJ: contributes to conception, acquisition and analysis, interpretation of data, and drafted the work. FBK: acquisition, analysis. AA: acquisition, analysis. JS: substantively revised the work. GA: substantively revised the work. VOR: contributes to conception, acquisition and analysis, interpretation of data, and drafted the work. All authors have approved the submitted version and the modified version that involves the author's contribution to the study; AND have agreed both to be personally accountable for the author's own contributions and ensure that questions related to the accuracy or integrity of any part of the work, even ones in which the author was not personally involved, are appropriately investigated, resolved and the resolution documented in the literature.

\section{Funding}

non-funded.

Availability of data and materials

All data generated or analyzed during this study are publicly available and included in this published article.

Ethics approval and consent to participate non-applicable.

Consent for publication non-applicable.

Competing interests

The authors declare that they have no competing interests. 


\section{Author details}

'Department of Microbiology, Faculty of Medicine, Kuwait University, P. O. Box 24923, 13110 Safat, Kuwait. ${ }^{2}$ Institute of Clinical Microbiology, University of Szeged, Szeged, Hungary.

\section{Received: 21 September 2019 Accepted: 9 January 2020} Published online: 15 January 2020

\section{References}

1. Garrett WS, Onderdonk AB. B. Bacteroides, Prevotella, Porphyromonas and Fusobacterium species (and other medically important anaerobic gramnegative bacilli). In: Mandell GL, Benett JE, Dolin R, editors. Mandell, Douglas and Bennett's principles and practice of infectious diseases. 8th ed. New York: Churchill Livingston; 2015. p. 2773-80.

2. Jandhyala SM, Talukdar R, Subramanyam C, Vuyyuru H, Sasikala M, Nageshwar RD. Role of the normal gut microbiota. World J Gastroenterol. 2015;21(29):8787-803. https://doi.org/10.3748/wjg. v21.i29.8787.

3. Myers LL, Firehammer BD, Shoop DS, Border MM. Bacteroides fragilis: a possible cause of acute diarrheal disease in newborn lambs. Infect Immunol. 1984:44(2):241-4.

4. Sack RB, Myers LL, Almeido-Hill J, Shoop DS, Bradbury WC, Reid R, et al. Enterotoxigenic Bacteroides fragilis: epidemiologic studies of its role as a human diarrhoeal pathogen. J Diarrhoeal Dis Res. 1992;10(1):4-9.

5. Akpinar M, Aktaş E, Cömert F, Külah C, Sümbüloğlu V. Evaluation of the prevalence of enterotoxigenic Bacteroides fragilis and the distribution bft gene subtypes in patients with diarrhea. Anaerobe. 2010;16(5):505-9. https://doi.org/10.1016/j.anaerobe.2010.08.002.

6. Mundy LM, Sears CL. Detection of toxin production by Bacteroides fragilis: assay development and screening of extraintestinal clinical isolates. Clin Infect Dis. 1996;23(2):269-76.

7. Chung GT, Franco AA, Wu S, Rhie GE, Cheng R, Oh HB, et al. Identification of a third metalloprotease toxin gene in extraintestinal isolates of Bacteroides fragilis. Infect Immun. 1999;67(9):4945-9.

8. Sears CL. The toxins of Bacteroides fragilis. Toxicon. 2001;39(11):1737-46.

9. Obiso RJ Jr, Azghani AO, Wilkins TD. The Bacteroides fragilis toxin fragilysin disrupts the paracellular barrier of epithelial cells. Infect Immun. 1997;65(4):1431-9.

10. Wu S, Lim KC, Huang J, Saidi RF, Sears CL. Bacteroides fragilis enterotoxin cleaves the zonula adherens protein, E-cadherin. Proc Natl Acad Sci USA. 1998;95(25):14979-84.

11. Sarvari KP, Soki J, Ivan M, Miszti C, Latkoczy K, Melegh SZ, et al. Detection of enterotoxin and protease genes among Hungarian clinical Bacteroides fragilis isolates. Anaerobe. 2017;48:98-102. https://doi.org/10.1016/j. anaerobe.2017.07.005.

12. Delahooke DM, Barclay GR, Poxton IR. A re-appraisal of the biological activity of bacteroides LPS. J Med Microbiol. 1995;42(2):102-12.

13. Rotimi VO, Verghese TL, Al-Sweih N, Khodakhast FB, Ahmed K. Influence of five anti-anaerobic antibiotics on endotoxin liberation by gram-negative anaerobes. J Chemother. 2000;12(1):40-7.

14. Prindiville TP, Sheikh RA, Cohen SH, Tang YJ, Cantrell MC, Silva J Jr. Bacteroides fragilis enterotoxin gene sequences in patients with inflammatory bowel disease. Emerg Infect Dis. 2000;6(2):171-4.

15. Toprak NU, Yagci A, Gulluoglu BM, Akin ML, Demirkalem P, Celenk T, et al. A possible role of Bacteroides fragilis enterotoxin in the aetiology of colorectal cancer. Clin Microbiol Infect. 2006;12(8):782-6.

16. Kato N, Kato H, Watanabe K, Ueno K. Association of enterotoxigenic Bacteroides fragilis with bacteremia. Clin Infect Dis. 1996;23(Suppl. 1):S83-6.

17. Choi VM, Herrou J, Hecht AL, Teoh WP, Turner JR, Crosson S, Bubeck, et al. Activation of Bacteroides fragilis toxin by a novel bacterial protease contributes to anaerobic sepsis in mice. Nat Med. 2016;22(5): 563-7. https://doi.org/10.1038/nm.4077.

18. Sóki J, Edwards R, Hedberg M, Fang H, Nagy E, Nord CE, et al. Examination of cfiA-mediated carbapenem resistance in Bacteroides fragilis strains from a European antibiotic susceptibility survey. Int J Antimicrob Agents. 2006; 28(6):497-502

19. Jamal W, Al Hashem G, Rotimi VO. Antimicrobial resistance among anaerobes isolated from clinical specimens in Kuwait hospitals: comparative analysis of 11-year data. Anaerobe. 2015;31:25-30. https://doi.org/10.1016/j. anaerobe.2014.08.012.

20. Jamal WY, Rotimi VO, Brazier JS, Johny M, Wetieh WM, Duerden BI. Molecular characterization of nitroimidazole resistance in metronidazole- resistant Bacteroides species isolated from hospital patients in Kuwait. Med Princ Pract. 2004;13(3):147-52.

21. Jamal W, Shahin M, Rotimi VO. Surveillance and trends of antimicrobial resistance among clinical isolates of anaerobes in Kuwait hospitals from 2002 to 2007. Anaerobe. 2010;16(1):1-5. https://doi.org/10.1016/j.anaerobe. 2009.04.004.

22. Magiorakos AP, Srinivasan A, Carey RB, Carmeli Y, Falagas ME, Giske CG, et al. Multidrug-resistant, extensively drug-resistant and pandrug-resistant bacteria: an international expert proposal for interim standard definitions for acquired resistance. Clin Microbiol Infect. 2012;18(3):268-81. https://doi.org/ 10.1111/j.1469-0691.2011. 03570.x.

23. Thornton RF, Kagawa TF, O'Toole PW, Cooney JC. The dissemination of C10 cysteine protease genes in Bacteroides fragilis by mobile genetic elements. BMC Microbiol. 2010;10:122. https://doi.org/10.1186/1471-2180-10-122.

24. Wexler HM. Bacteroides: the good, the bad and the nitty-gritty. Clin Microbiol Rev. 2007;20(4):593-621.

25. Kierzkowska M, Majewska A, Szymanek-Majchrzak K, Sawicka-Grzelak A, Mlynarczyk A, Mlynarczyk G. The presence of antibiotic resistance genes and bft genes as well as antibiotic susceptibility testing of Bacteroides fragilis strains isolated from inpatients of infant Jesus teaching hospital, Warsaw during 2007-2012. Anaerobe. 2019;56:109-15. https://doi.org/10.1016/j. anaerobe.2019.03.003.

26. Szoke I, Dósa E, Nagy E. Enterotoxigenic Bacteroides fragilis in Hungary. Anaerobe. 1997:3(2-3):87-9.

27. Scotto d'Abusco AS, Del Grosso M, Censini S, Covacci A, Pantosti A. The alleles of the bft gene are distributed differently among enterotoxigenic Bacteroides fragilis strains from human sources and can be present in double copies. J Clin Microbiol. 2000;38(2):607-12.

28. Claros MC, Claros ZC, Tang YJ, Cohen SH, Silva J Jr, Goldstein EJ, et al. Occurrence of Bacteroides fragilis enterotoxin gene-carrying strains in Germany and the United States. J Clin Microbiol. 2000;38(5):1996-7.

29. Nagy E, Urban E, Nord EC, on behalf of the ESCMID Study Group on Antimicrobial Resistance in Anaerobic Bacteria. Antimicrobial susceptibility of Bacteroides fragilis group isolates in Europe: 20 years of experience. Clin Microbiol Infect. 2011;17(3):371-9. https://doi.org/10.1111/j.1469-0691.2010.03256. x.

30. Wang FD, Liao CH, Lin YT, Sheng WH, Hsueh PR. Trends in the susceptibility of commonly encountered clinically significant anaerobes and susceptibilities of blood isolates of anaerobes to 16 antimicrobial agents, including fidaxomicin and rifaximin, 2008-2012, northern Taiwan. Eur J Clin Microbiol Infect Dis. 2014; 33(11):2041-52. https://doi.org/10.1007/s10096-014-2175-y.

31. Snydman DR, Jacobus NV, McDermott LA, Golan Y, Goldstein EJ, Harrell L, et al. Update on resistance of Bacteroides fragilis group and related species with special attention to carbapenems 2006-2009. Anaerobe. 2011;17(4): 147-51. https://doi.org/10.1016/j.anaerobe.2011.05.014.

32. Gao Q, Wu S, Xu T, Zhao X, Huang H, Hu F. Emergence of carbapenem resistance in Bacteroides fragilis in China. Int J Antimicrob Agents. 2019;53(6): 859-63. https://doi.org/10.1016/j.jjantimicag.2019.02.017.

33. Hurlbut S, Cuchural GJ, Tally FP. Imipenem resistance in Bacteroides distasonis mediated by a novel $\beta$-lactamase. Antimicrob Agents Chemother. 1990;34(1):117-20.

34. Sóki J, Fodor E, Hecht DW, Edwards R, Rotimi VO, Kerekes I, et al. Molecular characterization of imipenem-resistant, cfiA-positive Bacteroides fragilis isolates from the USA, Hungary and Kuwait. J Med Microbiol. 2004;53(Pt 5):413-9.

35. Yamazoe K, Kato N, Kato H, Tanaka K, Katagiri Y, Watanabe K. Distribution of the cfiA gene among Bacteroides fragilis strains in Japan and relatedness of cfiA to imipenem resistance. Antimicrob Agents Chemother. 1999;43(11): 2808-10.

36. Edwards R, Read PN. Expression of the carbapenemase gene (cfiA) in Bacteroides fragilis. J Antimicrob Chemother. 2000;46(6):1009-12.

37. Clinical and Laboratory Standards Institute: CLSI Publication Document M100-S28. Performance standards for antimicrobial susceptibility testing: Twenty eighth Informational Supplement, Vol. 34. Wayne: Clinical and Laboratory Standards Institute; 2018. p. No.1.

38. Eitel Z, Sóki J, Urbán E, Nagy E, the ESCMID Study Group on Anaerobic Infection. The prevalence of antibiotic resistance genes in Bacteroides fragilis group strains isolated in different European countries. Anaerobe. 2013;21: 43-9. https://doi.org/10.1016/j.anaerobe.2013.03.001.

\section{Publisher's Note}

Springer Nature remains neutral with regard to jurisdictional claims in published maps and institutional affiliations. 